Abstracta Iranica

Revue bibliographique pour le domaine irano-aryen

Volume 37-38-39 | 2018

Comptes rendus des publications de 2014-2016

\title{
Pier Giorgio Borbone, Pierre Marsone (eds.). Le christianisme syriaque en Asie centrale et en Chine
}

Christelle Jullien

\section{(2) OpenEdition \\ 12 Journals}

Édition électronique

URL : http://journals.openedition.org/abstractairanica/44579

DOI : $10.4000 / a b s t r a c t a i r a n i c a .44579$

ISBN : 1961-960X

ISSN : 1961-960X

Éditeur :

CNRS (UMR 7528 Mondes iraniens et indiens), Éditions de l'IFRI

Référence électronique

Christelle Jullien, « Pier Giorgio Borbone, Pierre Marsone (eds.). Le christianisme syriaque en Asie centrale et en Chine », Abstracta Iranica [En ligne], Volume 37-38-39 | 2018, document 23, mis en ligne le 30 décembre 2018, consulté le 28 septembre 2020. URL : http://journals.openedition.org/ abstractairanica/44579; DOI : https://doi.org/10.4000/abstractairanica.44579

Ce document a été généré automatiquement le 28 septembre 2020.

Tous droits réservés 


\title{
Pier Giorgio Borbone, Pierre Marsone (eds.). Le christianisme syriaque en Asie centrale et en Chine
}

\author{
Christelle Jullien
}

\section{RÉFÉRENCE}

Pier Giorgio Borbone, Pierre Marsone (eds.). Le christianisme syriaque en Asie centrale et en Chine. Paris : Geuthner, 2015, 307 p. (Études syriaques 12), ISBN 978-2-7053-3937-1.

1 Cet ouvrage rassemble les conférences d'une table ronde, augmentées de quelques études supplémentaires, sur l'histoire du christianisme d'expression syriaque en Asie centrale et en Chine. Les AA. soulignent la dimension plurielle de ce christianisme qui s'est développé dans ces régions en diverses expressions christologiques à la suite des mouvements missionnaires, des déportations, des déplacements de populations en raison des conflits armés ou des occupations commerciales. Mais ce sont surtout les missions syro-orientales initiées par les cadres hiérarchiques de l'Église de Perse qui furent à l'origine de l'expansion du christianisme et de l'implantation durable de communautés chrétiennes in situ - et le monachisme joua à cet égard un rôle non négligeable. Groupes chrétiens syro-orientaux de Mésopotamie, de Babylonie ou Perse, syro-orthodoxes de Syrie ou d'Arménie, melkites originaires de l'Antiochène, de la Syrie ou de la région de Hérat se sont ainsi disséminés parmi les populations turques, sogdiennes, mongoles ou chinoises, parfois en concurrence.

2 Quatre thèmes se dégagent parmi les articles classés en ordre plutôt chronologique. D'abord, une présentation séquencée du christianisme syriaque aux $\mathrm{VII}^{\mathrm{e}}-\mathrm{X}^{\mathrm{e}}$ siècles (P. Riboud, « Le christianisme syriaque à l'époque Tang », p. 41-61) et aux XIII ${ }^{\mathrm{e}}-\mathrm{XIV}^{\mathrm{e}}$ siècles dans la Chine des Mongols Yuan (L. Tang, « Le christianisme syriaque dans la Chine des Mongols Yuan : diffusion, statut des chrétiens et déclin (XIII ${ }^{\mathrm{e}}$-XIV ${ }^{\mathrm{e}}$ siècles) », p. 63-88). Deux études donnent en synthèse l'histoire de sa diffusion en Asie centrale : M. Dickens 
esquisse un panorama des diverses attestations connues dans le corpus des sources syriaques sur un créneau chronologique très vaste qui s'étend du $\mathrm{III}^{\mathrm{e}}$ siècle - avec une première mention dans l'œuvre du philosophe Bardesane d'Édesse - à la quasi extinction du christianisme dans le royaume timouride aux XVe-XVI siècles ( christianisme syriaque en Asie centrale », p. 5-39) ; P. G. Borbone décrit les relations entre les provinces dites “de l'extérieur” et l'Église syro-orientale (« Les "provinces de l'extérieur" vues par l'Église-mère », p. 121-157) dont le siège patriarcal se trouvait à Séleucie-Ctésiphon (Kokhē), et plus tard à Bagdad. Quelques articles ont trait aux données archéologiques, et spécialement aux inscriptions: B. Ashurov analyse les éléments d'une acculturation matérielle de l'Église d'Orient en Asie centrale à travers les témoignages des sources primaires (« Inculturation matérielle de l'Église d'Orient en Asie centrale : témoignages archéologiques », p. 161-183); A. Desreumaux présente la collection des pierres tombales du Turkestan conservées en France ( $«$ La collection des pierres tombales du Turkestan conservées à Paris et à Lyon », p. 237-256); T. Osawa et $\mathrm{H}$. Takahashi évoquent les inscriptions d'Ulaan Tolgoi de Mongolie centrale (« Le prince Georges des Önggüt dans les montagnes de l'Altaï de Mongolie : les inscriptions d'Ulaan Tolgoi de Doloon Nuur », p. 257-290). Un dernier thème porte sur la littérature et l'étude des fonds documentaires: une vue d'ensemble des textes (souvent fragmentaires) chrétiens en sogdien retrouvés dans l'oasis de Turfan et dans le monastère de Bulayïq (C. Barbati, «La documentation sogdienne chrétienne et le monastère de Bulayïq ", p. 89-120) et produits à partir du syriaque; une mise à jour des dernières analyses sur les manuscrits chrétiens de Qara Qoto (N. Smelova, « Manuscrits chrétiens de Qara Qoto : nouvelles perspectives de recherche ", p. 215-236) ; un examen des textes chrétiens en langue vieux-turc ou vieil-ouïghour (P. Zieme, « Notes sur les textes chrétiens en vieux ouïghour », p. 185-198) attestée entre les VII ${ }^{e}$ et XIII ${ }^{e}$ siècles ; une chrestomathie de la littérature chrétienne orientale à partir du VII ${ }^{\mathrm{e}}$ siècle en Chine (M. Deeg, "La littérature chrétienne orientale sous les Tang: un bref aperçu», p. 199-214). Cet ouvrage offre un panorama synthétique très utile des connaissances et des sources sur les communautés chrétiennes syriaques de ces régions.

\section{AUTEURS}

\section{CHRISTELLE JULLIEN}

CNRS, Mondes iranien et indien, Paris 